\title{
Comparison of Hamstring Flexibility between Patients with Chronic Lower Back Pain and the Healthy Individuals at the National Hospital of Sri Lanka
}

\author{
Hasarangi LBS and Jayawardana DGSK* \\ Deparment of Allied Health Sciences, Faculty of Medicine, University of Colombo, Sri Lanka
}

Received: May 24, 2018; Published: June 06, 2018

*Corresponding author: Jayawardana DGSK, Deparment of Allied Health Sciences, Faculty of Medicine, University of Colombo, Sri Lanka

\section{Abstract}

Introduction \& Objectives: A back pain lasting more than 12 weeks has been defined as a chronic low back pain. It is one of the leading causes for functional limitations in adult population. Due to the anatomical origin and insertion of hamstring; the lack of hamstrings flexibility decreases pelvic mobility which may lead to development of low back pain. The main aim of this study was to compare hamstrings flexibility between the patients with chronic lower back pain and healthy individuals at the National Hospital of Sri Lanka.

Methodology: Hospital based cross-sectional descriptive study was carried out with 100 participants; 50 patients with chronic low back pain and 50 age and gender matched healthy subjects with age between 40-60 years from National hospital of Srilanka. Active knee extension test was used to measure hamstrings flexibility.

Results: Each group consisted of 50 subjects and $66 \%$ were females. Mean age of the patients with chronic low back pain was $50.08 \pm 5.18$ years and mean age of the healthy people was $49.44 \pm 5.66$ years. The mean hamstrings flexibility for all subjects with chronic low back pain was $152.630 \pm 3.74$ for the right and $152.150 \pm 3.81$ for the left. Mean values for right and left hamstrings flexibility of healthy group were $159.480 \pm 3.42,159.330 \pm 3.07$ respectively. Hamstrings flexibility of the patients with chronic low back pain were significantly lower than the hamstrings flexibility of healthy people $(\mathrm{p}<0.05)$.

Conclusion: Hamstrings flexibility was significantly reduced among the patient chronic low back pain when compared to healthy individuals of same age and gender.

Keywords: Chronic lower back pain; Hamstring flexibility; Active knee extension

Abbreviations: CLBP: Chronic Low Back Pain; HF: Hamstrings Flexibility; HMC: Hamstring Muscle Complex; DRR: Department of Rheumatology and Rehabilitation; NHSL: National Hospital of Sri Lanka; AKE: Active Knee Extension;

\section{Background}

Chronic low back pain (CLBP) is defined as lower back pain lasting more than three months [1]. It affects $15-45 \%$ of the general population [2]. 50-80\% of adults have at least one episode of low back pain over the course of their lifetime [3]. Primary outcome of LBP is low back pain occurrence at a frequency of at least once a week within the past 6 months. Secondary outcomes contained treatments use for pain and disability. For most people affected by low back pain substantial pain or disability is short lived and they soon return to normal activities regardless of any advice or treatment they receive. A small proportion, however, develop chronic pain and disability [4]. There are many factors which are contributed for development of CLBP. Various factors include high growth spurt, reduced lumber lordosis, poor superficial abdominal muscle endurance, poor superficial back extensor muscle endurance, flexibility of back extensor muscle, length of Illiopsoas, Hamstring muscle flexibility and weakness and lack of motor control of deep trunk muscles, such as the lumbar Multifidus and Transversus abdominis muscles [4-6]. Age and sex, body composition, occupation, lifestyle, socio-economic status and smoking habits increased level of physical activity and work also act as contributing factors for lower back pain $[4,7]$. Arguments exist regarding association between above various physical characteristics and the occurrence of CLBP $[6,7]$.

Hamstrings flexibility (HF) is a term which is often used synonymously when referring to the ability of the hamstring muscle to 
be lengthened to their end range [8]. Anatomically, the Hamstring refers to the three posterior thigh muscles. The three muscles that constitute the hamstring muscle complex (HMC) are the Semitendinosus, the Semimembranosus and Biceps femoris muscles. They originate from the inferomedial impression on the upper part on the ischial tuberosity and insert on the upper part of the posterior surface of tibia [9]. The lack of hamstring flexibility has been associated with several complaints such as different spinal disorders, gait limitations, increased risk of falls, and susceptibility to musculoskeletal injuries such as CLBP [10]. Due to origin of HMC that is located on the ischial tuberosities of the pelvis, hamstring flexibility may influence pelvic rotation [11]. Restricted pelvic rotation can lead to decreased lumbar motion and repetitive micro trauma, which may be a factor in the development of CLBP [12].

In contrast previous studies have found that there was no relationship of HF and development of low back pain [13,14]. However, since the hamstrings and lumbar extensors have their muscular origin in the pelvis, there may be a possible relationship among these structures. So weakness or inflexibility of one structure may correspondingly change the strength and position of the other to maintain pelvis control, which may lead to development of low back pain [15]. Therefore the aim of the study was to further evaluate the prevalence of hamstrings flexibility in subjects with CLBP versus healthy individuals.

\section{Methodology}

Hospital based cross-sectional descriptive study was conducted at General and Special units of Department of Rheumatology and Rehabilitation (DRR), National Hospital of Sri Lanka (NHSL). Ethics approval was obtained from ethics review committee of faculty of medicine, university of Colombo, Sri Lanka. Permission was obtained to conduct the study from the director of NHSL, consultants in charge of the DRR general and DRR special units of NHSL and senior physiotherapist of DRR general and special units of NHSL. The participants were given the informed consent form with the information sheet. They were briefly stated about the nature of the study and intervention. Two groups were participated to the study and using consecutive method 50 (33 females; 17 males) were included to each group. Total sample was 100 participants.

Age between 40-60 years old patients with chronic lower back pain and gender matched healthy individuals were selected as the study population. In the CLBP group, Inclusion criteria were patients who were diagnosed as CLBP attending DRR, NHSL, having a history of lower back pain more than 3 month, subjects not involved in any flexibility exercises for hamstrings and subjects regularly used their analgesics. Subject with previous history of knee injury, knee deformity and fractures around knee joint with limited range of movement and radiating pain which start from back or knee joint, presence of any deformity of the spine (scoliosis etc.) or deformities in lower limbs and patients who have undergone surgery in the back were excluded.

In healthy individuals group, gender matched healthy consenting persons who accompany patients to the DRR clinic in NHSL during the study period; people who were not involved in any flex- ibility program were included. Exclusion criteria were people with a history of back pain or injury to back and previous history of knee injury, knee deformity and fractures around knee joint with limited range of movement and radiating pain. Distribution of demographic characteristics of the groups is shown in the Table 1 . There were no significant differences in age, height, and weight between the two groups $(\mathrm{P}>0.05)$.

Table 1: Distribution of demographic characteristics of participants.

\begin{tabular}{|l|c|c|c|c|c|}
\hline & \multicolumn{2}{|c|}{$\begin{array}{c}\text { Patients with CLBP } \\
\text { (n=50) }\end{array}$} & \multicolumn{2}{c|}{$\begin{array}{c}\text { Healthy individu- } \\
\text { als(n=50) }\end{array}$} & $\begin{array}{c}\text { Signifi- } \\
\text { cance }\end{array}$ \\
\hline & Mean & SD & Mean & SD & \\
\hline Age (years) & 50.08 & 5.18 & 49.44 & 5.66 & NS \\
\hline Height $(\mathrm{cm})$ & 157.62 & 5.16 & 157.26 & 5.04 & NS \\
\hline Weight $(\mathrm{Kg})$ & 64.16 & 7.32 & 62.48 & 7.10 & NS \\
\hline
\end{tabular}

CLBP, Chronic lower back pain; SD, Standard deviation; NS, Not significant $(\mathrm{P}>0.05)$

\section{Data Collection Tools}

Three tools were used for data collection; interviewer administered questionnaire and universal goniometer to assess the knee extension (to evaluate the hamstrings flexibility by using active knee extension test). Using an interview administered questionnaire, demographic and baseline data were taken including data about the condition of patient to be filled according to the data given by the subjects, data about diagnosis of the participants' conditions to be filled according to the diagnosis card. and data about CLBP of the participants to be filled only for the patients with CLBP according to the details they give.

\section{Procedure -Active Knee Extension (AKE) Test}

After completion of the informed consent form, each participant's hamstrings flexibility were assessed by using the active knee extension test (popliteal angle) with goniometer [4,14,15]. Subjects were placed supine. The contralateral lower limb remains extended on the bed throughout the test to minimize pelvic motion. To test the right side, for example, the tester ensured that the left lower limb remains extended. The right lower leg was flexed at the hip to $90^{\circ}$ angles actively. Initially the knee also was flexed at $90^{\circ}$. From this position, the amount of hip flexion was maintained at 90 degrees while the subjects were instructed to extend their right leg as far as possible until a mild stretch was felt, keeping their foot relaxed. The tester's hands maintained the subjects' thigh. A universal goniometer was taped to the lateral side of the knee joint was used to determine the popliteal angle. It was centered on the lateral femoral epicondyle and one arm was aligned with the greater trochanter of the femur and one with the lateral malleoli of the fibula. If any hip movement occurred the test was restarted.

The knee joint angle was measured using the pre-placed universal goniometer to the nearest degree when the subjects felt a mild stretch. The AKE test was used to measure both the right and left knees. The ankle of the tested leg was restrained in plantar flexion to avoid adverse neutral tension. The trials were conducted for 
each leg and the average of the three trials on each side was taken as final reading of popliteal angle.

\section{Data Analysis and Results}

Data was cleaned and entered to the SPSS (Statistical Product and Service Solutions).23.0 database. Demographic characteristics were analyzed using descriptive statistics. Comparison of hamstrings flexibility between two groups was made by using independent t-test. The mean HF for all subjects with CLBP was 152.630 (SD, \pm 3.74 ) for the right and $152.150( \pm 3.81)$ for the left. The mean value for average right and left HF of patient with CLBP was 152.400 (SD, \pm 3.67 ). Mean values for right and left HF of healthy group were 159.480 (SD, \pm 3.42 ), 159.330 (SD, \pm 3.07 ) respectively. The mean value for average of right and left HF of healthy people was 159.410(SD, \pm 3.18 ). Differences in HF of CLBP patients and healthy people were examined with Independent t-tests. This is shown in the Table 2 (Figure 1).

Table 2: Comparison of hamstrings flexibility between patients with CLBP and healthy individuals.

\begin{tabular}{|c|c|c|c|c|c|c|}
\hline & \multicolumn{2}{|c|}{$\begin{array}{c}\text { Patient with CLBP } \\
(\mathbf{n = 5 0 )}\end{array}$} & \multicolumn{2}{|c|}{$\begin{array}{c}\text { Healthy people } \\
(\mathbf{n = 5 0 )}\end{array}$} & & \\
\hline & Mean & $\begin{array}{c}\text { Std. } \\
\text { Deviation }\end{array}$ & Mean & $\begin{array}{c}\text { Std. } \\
\text { Deviation }\end{array}$ & T & $\begin{array}{c}\text { Sig. } \\
\text { (2-tailed) }\end{array}$ \\
\hline HF Right & 152.63 & 3.74 & 159.48 & 3.42 & -9.567 & $\mathrm{p}<0.05$ \\
\hline HF Left & 152.15 & 3.81 & 159.33 & 3.07 & -10.371 & $\mathrm{p}<0.05$ \\
\hline
\end{tabular}

HF, Hamstrings flexibility

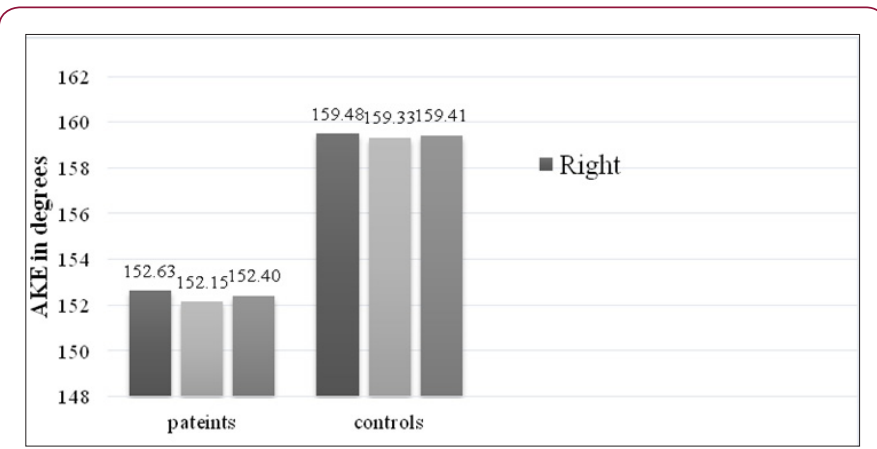

Figure 1: Comparison of hamstrings flexibility between patients with CLBP and healthy individuals.

\section{Discussion}

The hamstring flexibility is of significant clinical interest in the treatment of CLBP, especially because of the probable involvement of hamstrings flexibility in the occurrence of chronic lower back pain. It is not clear whether or not hamstring flexibility is a risk factor which is contributed for development of CLBP and association between hamstrings flexibility. According to the results of present study HF of patients with CLBP (the right and left lower limbs) were reduced than the HF of healthy group (the right and left lower limbs). This difference is statistically significant $(p<0.05)$. Above findings supports the more recent findings of Mistry et al. [15] that have been shown significant difference in HF of subjects with CLBP and normal individuals. Thus the research done by Mistry et al. [16] to compare the effect of active release technique and propriocep- tive neuromuscular facilitation on hamstrings flexibility, Pain and functional disability in patients having CLBP provide evidence that patients with CLBP have tight hamstrings.

But in contrast Koley and Likhi [14] have revealed that there was no association between HF and LBP. But in that study, they have included all the type of back pain. It may be confused about contribution of HF for developing CLBP. This finding [14] has been reported previously by Stutchfield and Coleman [13]. But the study population was not matched with present study. It has also previously been suggested that restricted pelvic rotation can lead to development of hamstrings tightness. So it will lead to restricted lumbar motion and repetitive micro trauma, so these factors together may be a factor in the development of LBP [12]. Above suggestions were supported by the more recent findings of Resi and Macedo [16] that have been shown a significant difference in the pelvic and lumber motion patients with LBP and asymptomatic controls. But they have found that HF had no influence in pelvic motion in both groups. Moreover no difference has been observed between LBP and asymptomatic controls. But the age of those participants were not matched with present study [17-19].

\section{Limitations of the Study}

Although there are many tools to measure HF, this study used the AKE test to measure HF. This measuring tool measures HF in degrees but some of the researches have given the HF values in other ways. Therefore the values in this study could not be compared with values in studies done elsewhere.

\section{Conclusion}

According to the attained results, this study has concluded that there was a significantly lower $(\mathrm{p}<0.05) \mathrm{HF}$ in patients with CLBP compared to the healthy people.

\section{References}

1. Ehrlich GE (2003) Low back pain. Bull World Health Organ 81(3): 671676.

2. Andersson GBJ (1999) Epidemiological features of chronic low-back pain. Lancet 354: 581-585.

3. Lawrence JP, Greene HS, Grauer JN (2006) (n.d.) Back Pain in Athletes. J Am Acad Orthop Surg 14: 726-735.

4. Feldman DE, Shrier I, Rossignol M, Abenhaim L (2001) Risk Factors for the Development of Low Back Pain in Adolescence 154(1): 30-36.

5. Nourbakhsh MR, Arab MA (2002) Relationship Between Mechanical Factors and Incidence of Low Back Pain. J Orthop Sports Phys Ther 32(9): 447-460.

6. Koley S, Kaur J, Sandhu JS (2010) Biological Risk Indicators for Nonspecific Low Back Pain in Young Adults of Amritsar. Punjab India 2(1): 43-48.

7. Koley S, Taran T, Sandhu NK (2009) An Association of Body Composition Components with the Menopausal Status of Patients with Low Back Pain in 1(2): 129-132.

8. Cornbleet SL, Woolsey NB (1996) Assessment of hamstring muscle length in school aged children using the sit and reach test and the inclinometer of hip joint angle. Physical Therapy 76(8): 850-855.

9. Chaurasiya BD (2004) Human anatomy regional and applied. 3rd ed. vol. 2. CBS Publishers \& Distributors, New Delhi, India, p. 74. 
10. Mayorga-Vega D, Merino-Marban R, Viciana J (2014) Criterion-related validity of sit-and-reach tests for estimating hamstring and lumbar extensibility: A meta-analysis. Journal of Sports Science and Medicine 13(1): 1-14.

11. Bellew S, Ford H, Shere E (2010) The Relationship between Hamstring Flexibility and Pelvic Rotation around the Hip during Forward Bending The Plymouth Student Journal of Health \& Social Work (2): 19-29.

12. Esola MA, McClure PW, Fitzgerald GK, Siegler S (1996) Analysis of Lumbar Spine and Hip Motion during Forward Bending in Subjects with and without a history of Low Back Pain. Spine 21(1): 71 -78.

13. Stutchfield BM, Coleman S (2006) The relationships between hamstring flexibility, lumbar flexion and low back pain in rowers. European Journal of Sport Science 6(4): 37-41.

14. Koley S, Likhi N (2011) No Relationship between Low Back Pain and Hamstring Flexibility, Anthropologist 13(2): 117-120.
15. Mistry GS, Vyas NJ, Sheth MS (2014) Comparison of hamstrings flexibility in subjects with chronic low back pain versus normal individuals. J Clin Exp Res 2 (1): 85-88.

16. Reis JFJ, Macedo AR (2015) Influence of Hamstring Tightness in Pelvic, Lumbar and Trunk Range of Motion in Low Back Pain and Asymptomatic Volunteers during Forward Bending. Asian Spine J 9: 535.

17. Bedard RJ, Kim K, Grindstaff TL, Hart JM (2013) Increased Active Hamstring Stiffness After Exercise in Women With a History of Low Back Pain p: 47-52.

18. Esola MA, McClure PW, Fitzgerald GK, Siegler S (1996) Analysis of Lumbar Spine and Hip Motion during Forward Bending in Subjects with and without a history of Low Back Pain. Spine 21(1): 71 -78.

19. Mistry GS, Vyas NJ, Sheth MS (2015) Comparison Of The Effect Of Active Release Technique Versus Proprioceptive Neuromuscular Facilitation Stretching (Modified Hold-Relax) On Hamstring Flexibility In Patients Having Chronic Low Back Pain p. 6.

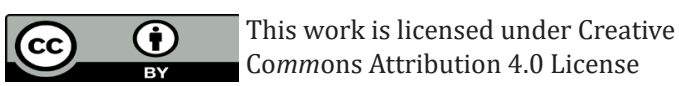

Submission Link: https://biomedres.us/submit-manuscript.php

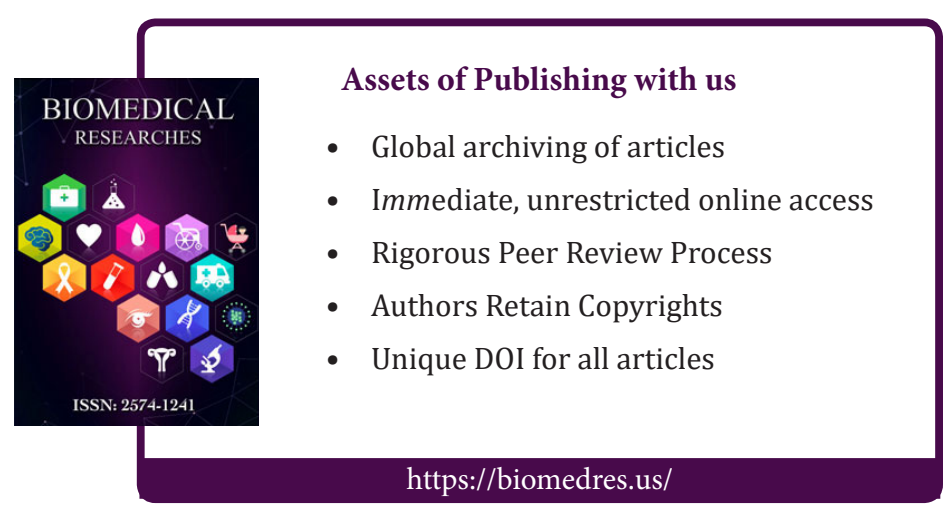

